\title{
Pineau, Marisa (Ed.) (2011): La Ruta del Esclavo en el Río de la Plata. Aportes para el diálogo intercultural. Buenos Aires: Eduntref. 444 pp. ISBN: 978-987-1172-67-2
}

La Ruta del Esclavo en el Río de la Plata. Aportes para el diálogo intercultural -libro que recoge las ponencias del Seminario Internacional que, con el mismo nombre, se realizó en Buenos Aires en octubre de 2009- es una contribución, desde la perspectiva rioplatense, al Proyecto La Ruta del Esclavo, impulsado por la Unesco en 1993 a propuesta de Haití y de varios países africanos, con el objetivo de promover y coordinar estudios sobre la trata de esclavos y la esclavitud, que han dejado indelebles huellas materiales y espirituales en las sociedades involucradas.

La trata negrera suscita vivo interés a causa del silencio universal a la que fue confinada, de la violencia extrema que entrañó, del ignominioso relato que la justificó y de los intercambios paradójicos que generó. Despierta, asimismo, interrogantes sobre algunas de las cuestiones más candentes del mundo actual, como los derechos humanos, la construcción de identidades, la ciudadanía y el pluralismo cultural. Considerada como la mayor tragedia de la historia de la humanidad por su duración, amplitud y cruel forma de mundialización que significó, la trata de esclavos ha provocado profundas transformaciones a nivel mundial que explican, en parte, las configuraciones geopolíticas y socioeconómicas del mundo actual. http://www.unesco.org/new/es/social-and-humansciences/themes/slave-route/

La Ruta del Esclavo en el Río de la Plata: aportes para el diálogo intercultural, se propuso difundir las más actuales investigaciones sobre el tema en la región -considerada de manera amplia y con perspectiva histórica- de especialistas de la Argentina, de países vecinos, como Uruguay y Brasil, y de otras regiones del mundo directamente involucradas en la temática, como Haití, Estados Unidos, Cuba, Nigeria, Costa de Marfil, España y Francia.

La dirección académica de Marisa Pineau, compiladora a su vez de los trabajos que incluye el libro, se propuso trazar un panorama general del estado actual de los conocimientos sobre la cuestión en el Río de la Plata, con textos que recogen miradas y opiniones diversas, e incluso encontradas, pero siempre enriquecedoras, abordando cuestiones como la vinculación del Proyecto internacional de la Ruta del Esclavo con el diálogo intercultural de África y América Latina; la presencia africana en el Río de la Plata; las consecuencias del tráfico de esclavos en las sociedades africanas; el patrimonio cultural de los africanos en el Río de la Plata y los sitios de memoria de la esclavitud en el Río de la Plata.

De hecho, el Proyecto "La Ruta del Esclavo" de la Unesco, lanzado oficialmente en 1994 desde la ciudad de Ouidah (Benin), uno de los centros emblemáticos del tráfico de esclavos en el Golfo de Guinea, promueve -entre otros programas científicos pluridisciplinarios- uno destinado a la preservación de lugares y edificios de memoria y su promoción a través del turismo cultural, así como la creación de inventarios y la recopilación de documentos escritos y tradiciones orales, que promuevan de manera significativa una mejor integración social y comprensión de la historia y la tragedia de la trata de esclavos a nivel global.

El libro organiza los trabajos y presentaciones en 7 partes.

La primera, dedicada a las conferencias magistrales, incluye Africa y la esclavitud en el contexto transnacional (Toyin Falola, Nigeria); La Ruta del esclavo y el diálogo intercultural Africa/América latina (Jesús Guanche Pérez, Cuba); y La presencia africana en el Río de la Plata (Dina Picotti, Argentina).

La segunda parte, titulada Aproximaciones historiográficas, abarca Rompiendo el silencio y la invisibilidad africanos en la historiografía argentina. La esclavitud en el Río de la Plata (Marta Beatriz Goldberg, Argentina); y Por una historia comparada de la esclavitud moderna (Eduardo França Paiva, Brasil).

La tercera parte está dedicada a La trata de esclavos y la esclavitud en el Río de la Plata, con las siguientes contribuciones: El tráfico de esclavos hacia el Rio de la Plata a fines del período hispánico (Miguel Angel Rosal, Argentina); Esclavitud en Paraguay: las estancias jesuiticas (Ignacio Telesca, Argentina); La trata de negros en el Río de la Plata: restricciones legales y contrabando en la época colonial (JeanArsène Yao, Costa de Marfil); Esclavos, libres y libertos del Rio de la Plata. Un lento acceso a la ciudadanía (Liliana Crespi, Argentina).

La cuarta parte aborda Vida cotidiana e historia social de africanos y de afrodescendientes, con los siguientes trabajos: Vida cotidiana y conflicto: la población afrodescendiente ante la justicia (Silvia Mallo, Argentina); Negros, indios y afromestizos en el Tucumán colonial. Una aproximación a las identidades étnicas y al diálogo intercultural (Florencia Guzmán, Argentina); Cuando la pobreza iguala a blancos y negros en el Buenos Aires de 1858. Breves historias de vida del asilo de mendigos (José Luis Moreno, Argentina); Negras historias: trabajadores esclavizados en la frontera uruguaya. Presencia africana en el norte del Uruguay (Eduardo R. Palermo, Uruguay); Afrodescendientes: los que regresaron al Africa (Mónica Lima e Souza, Brasil); Afrodescencientes y esfera pública en el Buenos Aires de fines del siglo XIX (Lea Geler, Argentina). 
La quinta parte está dedicada al tema Patrimonio cultural de los africanos en el Río de la Plata, e incluye: Construcción de una tradición negra. Estigmas y emblemas entre los devotos de San Baltazar (Norberto Pablo Cirio, Argentina); La presencia africana en las letras de la vanguardia del Río de la Plata (Sergio Baur, Argentina); La sociedad del tango y el bombo, que no reconoce qué es un tango ni qué es un bombo (Daniel Schávelzon, Argentina); La presencia de esclavos en las estancias jesuiticas: el caso de Alta Gracia, Córdoba (Mónica Risnicoff de Gorgas, Argentina); Sitios de memoria de la esclavitud en Uruguay (Ana Fraga, Uruguay); e Influencias africanas en las músicas del Rio de la Plata (Luis Ferreira, Argentina).

La sexta parte aborda Tres experiencias de gestión del patrimonio cultural en el mundo, con los siguientes trabajos: Experiencias de rutas en el espacio cultural iberoafricano e iberoamericano (Jordi Tresserras, España); El proyecto Unesco de sitios de memoria en el Caribe latino (Laënnec Hurbon, Haiti); y La ruta de las aboliciones de la esclavitud en Francia (Philippe Pichot, Francia).

La séptima y última parte, titulada Los afrodescendientes en la actualidad contiene La diáspora africana en la Argentina (Miriam Gomes, Argentina); y La Aecid y su programa de cooperación con afrodescendientes (Noelia Monge Vega, España).

\section{Invisibilizados}

Como destaca Dina Picotti, en la Argentina, dada la menor presencia de esclavos africanos y sus descendientes, si se la compara con el Caribe, Brasil o la zona andina central, y su poca visibilidad posterior, suele escucharse aún que "aquí no hay negros", porque los que hubo habrían desparecido por distintas causas y que por ello poco o nada habrían influido en nuestra identidad. Sin embargo -aclara- tal como lo prueba una documentación nada despreciable y múltiples signos físicos y culturales, llegaron a la Argentina en mayor número del que se cree y participaron activamente en los diversos ámbitos de la vida de nuestras sociedades a lo largo de su historia, de un modo más significativo de lo que se percibe o se quiere reconocer.

Miguel Angel Rosal cita investigaciones efectuadas por el historiador uruguayo Alex Borucki (2008), que consignan que, en sólo 35 años (entre 1777, un año después de la creación del Virreinato del Rio de la Plata, y 1812, año de la abolición de la trata negrera) 60.393 esclavos provenientes de Brasil y Africa, en 582 viajes, fueron desembarcados en las orillas del Plata, especialmente en Montevideo, único puerto autorizado para efectuar la trata desde que, en 1791, se había autorizado la introducción de esclavos. Durante el lapso mencionado, la población de Buenos Aires creció el $34 \%$, en tanto que la población esclava creció el $101 \%$. Para Montevideo, hacia fines del siglo XVIII y principios del siguiente, las cifras son más espectaculares: $119 \%$ y $486 \%$, respectivamente. A fines del período colonial los esclavos constituían el 33 $\%$ de la población de Buenos Aires (alrededor de 43 mil habitantes) y de Montevideo (poco más de 11 mil).

Marta Beatriz Goldberg señala que, bajo la denominación de "negros", se "cosificó" a seres humanos deportados de Africa y pertenecientes a numerosos grupos étnicos y lingüísticos. Los que trajeron al Río de la Plata- afirma- eran bantúes y provenían especialmente de Angola, el Congo y Mozambique. Una vez desembarcados en Buenos Aires eran vendidos como "negros bozales" o "costal de huesos". Los propietarios los bautizaban y les ponían un nombre y su propio apellido, como señal de pertenencia. La mayoría de ellos eran transportados por comerciantes, a menudo portugueses, desde Buenos Aires hacia la ciudad de Córdoba del Tucumán, donde se bifurcaba el camino para dirigirse, en un caso a Chile y, en el otro al Alto Perú (hoy Bolivia). En el trayecto se abastecían los mercados del interior.

La participación africana en las sociedades americanas actuales puede verse y rastrearse en diversas expresiones culturales, que hoy forman parte del patrimonio intangible. La música, la literatura, las tradiciones orales y la religión, son manifestaciones particularmente relevantes. Por consiguiente, el libro también aborda los distintos ámbitos del patrimonio intangible rioplatense enriquecidos por las culturas africanas, generalmente ignoradas o negadas, a pesar de sus valiosos aportes. Se considera que más de 10 millones de esclavos fueron introducidos en América en los cuatro siglos de trata transatlántica, por lo que es imposible negar la importancia de su influencia en el despliegue sociocultural del continente.

Pero la esclavitud tiene su historia reciente, lo que Toyin Falola describe como, "un aspecto sucio del llamado moderno Siglo XX". El catedrático nigeriano, profesor de la Universidad de Texas, en Austin, sostiene que la esclavitud y la trata de esclavos sobrevivieron al siglo XIX ya que Brasil y Cuba no promulgaron leyes para abolirla hasta finales de la década de 1880. Sin embargo, la abolición del comercio transatlántico de esclavos a comienzos del siglo XIX, no se tradujo en la abolición de la esclavitud en Africa. En muchas partes de este continente continuaron las prácticas asociadas con la esclavitud y otras formas de servidumbre hasta bien entrado el siglo XX. Para Falola, aunque por un lado contribuyeron a su abolición, por el otro los gobiernos coloniales europeos hicieron lo necesario para que la esclavitud sobreviviera. La demanda internacional de productos africanos dio lugar al uso intensivo de mano de obra esclava para producir y transportar materias primas a las ciudades costeras. Como resultado de ello, la esclavitud tuvo una muerte lenta y sobrevivió, en algunos lugares del Africa, hasta la década de 1930.

\section{Aporte}

El Programa Unitwin y de Cátedras Unesco es la actividad concreta intersectorial más importante de la organización en el campo de la educación superior. Las 
Cátedras actúan como socias estratégicas de la Unesco en relación a sus distintos proyectos - como en este caso La Ruta del Esclavo- y programas de actividades.

Tanto el libro La Ruta del Esclavo en el Río de la Plata. Aportes para el diálogo intercultural, como una publicación posterior, Huellas y legados de la esclavitud en las Américas (2012), también resultado de un seminario internacional del mismo nombre realizado en 2010 -ambos organizados en Buenos Aires por la Cátedra UNESCO de Turismo Cultural Untref-Aamnba- persiguieron, en este contexto, contribuir a la comprensión de las manifestaciones culturales que surgieron como resultado del diálogo entre los africanos y los pueblos que se encontraron en las rutas de la esclavitud en el extremo sur de América, y ser un aporte a la reflexión sobre los efectos traumáticos de la trata de esclavos y la esclavitud con sus trágicas consecuencias, que aún perduran.

Carmen María Ramos

Cátedra Unesco de Turismo Cultural Untref-Aamnba. catedraunesco@turismoculturalun.org.ar

Recibida: 20-02-2017

Aceptada: 27-03-2017

(c) (1) (3) 